\title{
27001
}

\section{AEROSOL REACTORS FOR THIN FILM DEPOSITION AND THEIR APPLICATION TO ZnS:CI DOPED FILMS}

\author{
F.J. Martin, H. Albers, P.V. Lambeck and Th.J.A. Popma \\ MESA Research Institute, Light wave Devices Group, University of Twente, \\ P.O.Box 217,7500 AE Enschede, THE NETHERLANDS
}

\author{
KEYWORDS \\ Aerosol reactor, thin films, spray pyrolysis, aerosol deposition, $\mathrm{CVD}, \mathrm{ZnS}, \mathrm{Cl}$, luminescent materials
}

\section{INTRODUCTION}

Thin films of different materials like metals, oxides, sulphides, etc., can be deposited by the Chemical Aerosol Deposition Technology (CADT). A liquid aerosol is used to transport the chemical reactants to the vicinity of a heated substrate. Conditions are set to obtain an heterogeneous reaction (CVD mode) between the evaporated reactants and the substrate (Maatman et al. 1988). The quality of the films is therefore comparable to those made by CVD or MOCVD with the advantage of being an inexpensive technique.

Two different aerosol reactors have been used to deposit $\mathrm{ZnS}: \mathrm{Cl}$ thin films: an stagnation point flow reactor and a hot wall vertical aerosol reactor.

\section{EXPERIMENTAL}

For both reactors a standard solution $0.1 \mathrm{M}$ of $\mathrm{ZnCl}_{2}$ and $0.1 \mathrm{M}$ of $\left(\mathrm{NH}_{2}\right)_{2} \mathrm{CS}$ in $\mathrm{CH}_{3} \mathrm{CH}_{2} \mathrm{OH}$ has been mostly used. The solution is pumped $(0.8-1.5 \mathrm{ml} / \mathrm{min}$ per atomiser) to the ultrasonic atomiser (frequency of $3 \mathrm{MHz}$ ) and

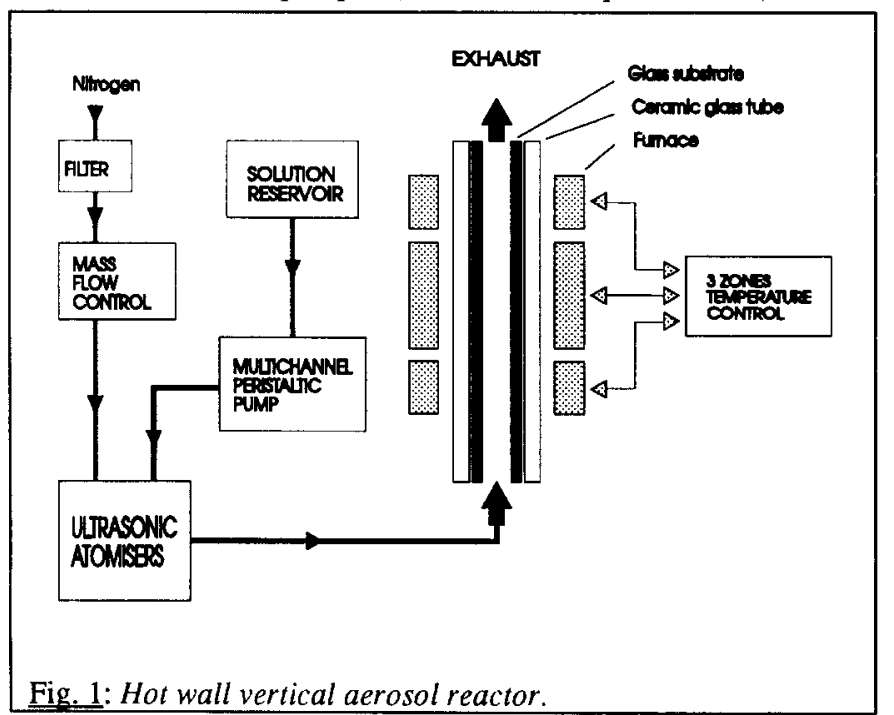
the aerosol formed is dragged with nitrogen (1-3 $\mathrm{l} / \mathrm{min}$ per atomiser) to the reactor.

The stagnation point flow reactor used in this work has been already described elsewhere (Martin et al, 1991).

The vertical hot wall aerosol reactor (fig. 1) uses a set of two or four ultrasonic atomisers. The reaction tube is a flat ceramic glass tube; the substrates are two glass plates of the same length of the tube and fixed at its inner sides; the distance between the substrate surfaces is $3 \mathrm{~mm}$. Laminar flow can be therefore developed. The tube is placed inside a three zones vertical furnace where the aerosol flows upwards.

The deposited layers have been analysed by optical fluorescence microscopy, SEM, fluorescence spectrophotometer, XRD and EDX.

\section{RESULTS}

Thin luminescent films have been successfully obtained with both configurations.

Films obtained with optimised conditions in the stagnation point flow configuration show polycrystalline hexagonal structure (XRD, SEM) with preferential growth in the c-axes: (002) plane parallel to the substrate. At $550^{\circ} \mathrm{C}$ (upper temperature used due to glass substrate limitations) we obtain the maximum photoluminescence. The luminescent centre is expected to be the SA luminescence of $\mathrm{ZnS}: \mathrm{Cl}$. This is a broad band luminescence centre and consist of a $\mathrm{Zn}^{2+}$ vacancy and one of the charge-compensating coactivators associated at one of the nearest substitutional sites. The acceptor state in the pair emission originates from a $\mathrm{Zn}^{2+}$ vacancy with which a coactivator is associated, while the donor state from an isolated coactivator (Era et al., 1970). These films have 
also been doped by adding $\mathrm{CuCl}_{2}$ to the standard solution in different concentrations. The photoluminescence shift from blue $(450 \mathrm{~nm})$ to greenish blue $(500 \mathrm{~nm})$ as the $\mathrm{CuCl}_{2}$ concentration in solution increases (results should be published elsewhere): the expected luminescence centre is the green-copper luminescence centre with
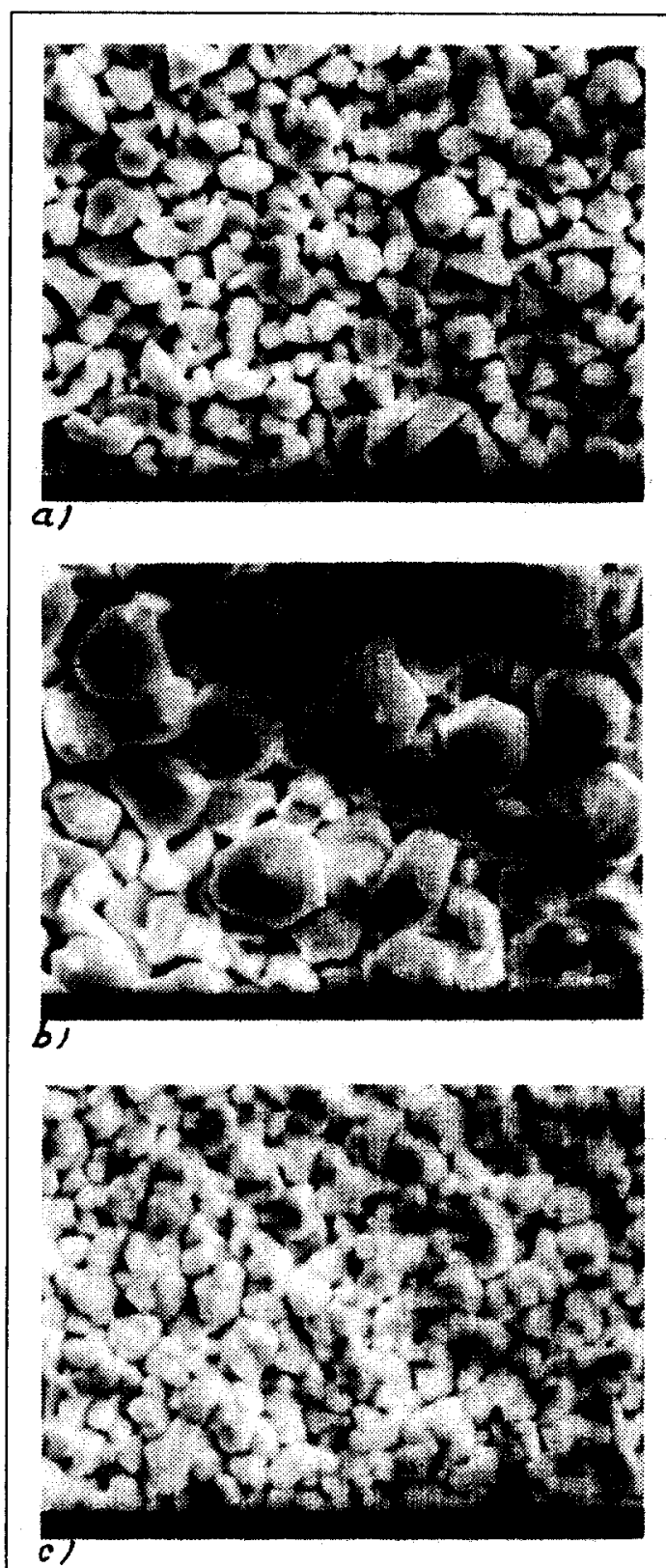

Fig. 2: SEM pictures of a $\mathrm{ZnS}$ thin film deposited at $550^{\circ} \mathrm{C}$ (flat zone): a) $16 \mathrm{~cm}$; b) $17.5 \mathrm{~cm}$ and c) $21.5 \mathrm{~cm}$ from the bottom of the reaction tube. chlorine ions as coactivators. The intensity measured is about equal to that of commercial $\mathrm{ZnCdS}$ : $\mathrm{Ag}$ powder (530 $\mathrm{nm}$ emission).

The vertical hot wall aerosol reactor has been also successfully applied to deposit thin luminescent films of $\mathrm{ZnS:Cl}$. This configuration allows to develop a laminar flow inside the tube because convection has the same direction of the forced flow. When the aerosol concentration is too high $\left(\mathrm{N}_{2}\right.$ flow $<4 \mathrm{l} / \mathrm{min}$, solution pump speed $>1.6 \mathrm{ml} / \mathrm{min}$ ), homogeneous reaction takes place, and a powder deposit is formed. When the $\mathrm{N}_{2}$ flow is equal or higher than $6 \mathrm{l} / \mathrm{min}$, the main deposition is from heterogeneous reaction: in this case luminescent $\mathrm{ZnS}: \mathrm{Cl}$ films are obtained. Thickness and luminescence are strong dependent on temperature. As can be seen by the SEM pictures (fig $2 a, b, c$ ) taken of the layer on different height the morphology of a deposit at $550{ }^{\circ} \mathrm{C}$ (flat zone temperature) change from a high porous layer ( $2 a)$ to a closed layer $(2 c)$, with between both a zone of big and small columns $(2 b)$. The growth rate is also a function of the height in the reactor and has a maximum at the position of the SEM picture in fig. $2 b$. The causes of these different growth regimes must be the temperature, the temperature gradient and the gas phase concentration of reactants. The effect of these parameters will be studied in more detail. The blue intense luminescence is associated to the (2c) structure as could be seen by fluorescence microscopy pictures.

Acknowledgement: The authors thank the experimental work realised by $K$. Bulut and the SEM and EDX analysis made by $B$. Otter.

\section{REFERENCES}

Era, K., S. Shionoya, Y. Washizawa and H. Ohmatsu (1968), J. Phys. Chem. Solids, Vol. 29, pp. 1843-1857. Maatman, D., W. Gruisinga, P.V. Lambeck and Th.J.A. Popma (1988), Journal of Aerosol Science, Vol. 19, No. 7, pp. 1369-1372.

Martin, F.J., H. Albers, P.V. Lambeck, G.M.H. van de Velde and Th.J.A. Popma (1990), Journal of Aerosol Science, Suppl. 1, Vol. 22, S435-\$438. 